\title{
Symbiont carbon and nitrogen assimilation in the Cassiopea-Symbiodinium mutualism
}

\author{
Christopher J. Freeman ${ }^{1, *}$, Elizabeth W. Stoner ${ }^{2}$, Cole G. Easson ${ }^{3}$, \\ Kenan O. Matterson ${ }^{3}$, David M. Baker ${ }^{4}$ \\ ${ }^{1}$ Smithsonian Marine Station, 701 Seaway Drive, Fort Pierce, Florida 34949, USA \\ ${ }^{2}$ Loxahatchee River District, 2500 Jupiter Park Drive, Jupiter, Florida 33458, USA \\ ${ }^{3}$ Department of Biology, University of Alabama at Birmingham, 1300 University Blvd, Birmingham, Alabama 35294, USA \\ ${ }^{4}$ The Swire Institute of Marine Science, School of Biological Sciences \& Department of Earth Science, \\ University of Hong Kong, Hong Kong, PR China
}

\begin{abstract}
Symbiotic interactions in the marine environment have long been represented by mutualisms between photosymbionts and benthic marine invertebrates like corals and sponges. Although 'upside-down' epibenthic jellyfish in the genus Cassiopea also derive a substantial metabolic benefit from abundant communities of the dinoflagellate symbiont Symbiodinium, comparatively little is known about the efficiency of carbon $(\mathrm{C})$ and nitrogen $(\mathrm{N})$ assimilation within the Cassiopea holobiont. Using standardized $6 \mathrm{~h}$ incubations with ${ }^{13} \mathrm{C}$ - and ${ }^{15} \mathrm{~N}$ - enriched compounds, we assessed symbiont $\mathrm{C}$ and $\mathrm{N}$ assimilation in both oral arm and bell tissue of $C$. xamachana under light and dark conditions. Carbon fixation was light dependent and highest in the photosymbiont-rich oral arm tissue. In contrast, ${ }^{15} \mathrm{NO}_{3}$ assimilation was light independent in both tissue types and was highest in bell tissue that was sparsely colonized by photosymbionts. This, coupled with higher bell tissue ${ }^{15} \mathrm{~N}$ enrichment under dark conditions, implicates nonphotosynthetic microbes in Cassiopea $\mathrm{N}$ metabolism. This zonation of microbial activity may allow C. xamachana to simultaneously fix $\mathrm{C}$ and assimilate ambient or porewater $\mathrm{N}$ released during Cassiopea pumping activity. Although C. xamachana may utilize symbiont-derived $\mathrm{N}$, lower ${ }^{15} \mathrm{~N}$ enrichment relative to $\mathrm{C}$ fixation suggests that Cassiopea may also rely on exogenous sources of $\mathrm{N}$ for growth. This study provides initial evidence that the efficiency of symbiont metabolism within Cassiopea jellyfish is comparable to, or exceeds, that of other common benthic marine invertebrates, supporting the contention that Cassiopea have an important role in the productivity and nutrient dynamics within their local environment.
\end{abstract}

KEY WORDS: Jellyfish · Symbiosis · Photosymbionts · Nutrient dynamics · Stable isotopes · Carbon fixation $\cdot{ }^{13} \mathrm{C}$ and ${ }^{15} \mathrm{~N}$ tracers

\section{INTRODUCTION}

By hosting abundant symbiont communities, many eukaryotes supplement heterotrophic feeding with diverse microbial metabolic pathways, allowing for survival and growth in nutrient-limited ecosystems (Moran 2007). These symbioses have long been re- presented by the mutualism between dinoflagellate symbionts within the genus Symbiodinium and diverse host species (Baker 2003) on shallow tropical coral reefs. In these systems, photosymbiont carbon (C) fixation often exceeds the energy requirements of the host, fueling the growth and proliferation of reefbuilding corals, octocorals, and sponges (Muscatine 
\& Porter 1977, Weisz et al. 2010, Freeman et al. 2013, Baker et al. 2015).

In addition to these common members of reef communities, Symbiodinium plays an important role in the ecology and evolution of other marine invertebrates (Baker 2003). For instance, Cassiopea spp. jellyfish host an abundant Symbiodinium community within their oral appendages (Verde \& McCloskey 1998). These 'upside-down' jellyfish orient their oral arms towards the surface to expose their photosymbionts to downwelling sunlight, while their aboral (bell) surface pulses against the benthos to generate water flow and draw out sediment-locked nutrients (Welsh et al. 2009, Jantzen et al. 2010). In exchange for a safe, nutrient-rich habitat, these photosymbionts may satisfy $\sim 160 \%$ of the host's metabolic C demand (Verde \& McCloskey 1998) and support a growth rate of about $3 \% \mathrm{~d}^{-1}$ (Welsh et al. 2009).

Assimilation of dissolved inorganic nitrogen (DIN) by Cassiopea spp. and other symbiotic jellyfish also implies that these photosymbiont communities play a role in holobiont (unit including both host and symbiont cells; Zilber-Rosenberg \& Rosenberg 2008) N metabolism and cycling (Welsh et al. 2009, Baker et al. 2013). Under saturating irradiance, DIN was removed from the surrounding seawater by Cassiopea spp. (Welsh et al. 2009) and assimilated and incorporated into the biomass of Linuche unguiculata, another symbiotic scyphozoan (Wilkerson \& Kremer 1992). This latter study used ${ }^{15} \mathrm{~N}$-labeled DIN to show that $\mathrm{NH}_{4}{ }^{+}$was taken up over $10 \times$ faster than $\mathrm{NO}_{3}$ (Wilkerson \& Kremer 1992). Uptake (Jantzen et al. 2010) and assimilation (Wilkerson \& Kremer 1992) of $\mathrm{NH}_{4}{ }^{+}$under dark conditions, however, also implicates non-photosynthetic microbes (Pitt et al. 2009) or host cells in $\mathrm{NH}_{4}{ }^{+}$assimilation (Grover et al. 2002). This, coupled with a recent report ascribing $\mathrm{NO}_{\mathrm{x}}$ release from Cassiopea individuals held in the dark to the presence of nitrifying bacteria (Welsh et al. 2009), suggests that holobiont $\mathrm{N}$ metabolism within symbiotic scyphozoans is complex.

Despite this previous research, little is known about the efficiency of symbiont $\mathrm{C}$ and $\mathrm{N}$ assimilation in the Cassiopea spp. holobiont (Pitt et al. 2009). To address this, we isolated the autotrophic pathway by incubating C. xamachana for $6 \mathrm{~h}$ in seawater spiked with $\mathrm{NaH}^{13} \mathrm{CO}_{3}$ and $\mathrm{Na}^{15} \mathrm{NO}_{3}$ following standardized methods previously applied to sponges (Freeman et al. 2013) and octocorals (Baker et al. 2015). Because Symbiodinium abundance is heterogeneous throughout Cassiopea spp. (Verde \& McCloskey 1998, Estes et al. 2003), we assessed ${ }^{13} \mathrm{C}$ and ${ }^{15} \mathrm{~N}$ assimilation in regions of $C$. xamachana where both dense and sparse photosymbiont communities were observed. In addition, because non-photosynthetic microbes may be present within the Cassiopea spp. holobiont, and may contribute to the overall holobiont $\mathrm{C}$ and $\mathrm{N}$ metabolism (Verde \& McCloskey 1998), we investigated $\mathrm{C}$ and $\mathrm{N}$ assimilation under both light and dark conditions. Finally, we also followed the fate of assimilated $\mathrm{C}$ and $\mathrm{N}$ over time by measuring the ${ }^{13} \mathrm{C}$ - and ${ }^{15} \mathrm{~N}$ - enrichment in C. xamachana maintained under natural conditions for $6 \mathrm{~h}$ and $18 \mathrm{~h}$ after exposure to enriched compounds. We hypothesized that ${ }^{13} \mathrm{C}$ and ${ }^{15} \mathrm{~N}$ enrichment would be light dependent, highest in the oral arms where Symbiodinium abundance is greatest, and would be highest in both tissue types immediately after the initial $6 \mathrm{~h}$ exposure to enriched compounds.

\section{MATERIALS AND METHODS}

\section{Collections and processing}

Small ( 8-11 cm bell width) Cassiopea xamachana were collected from a shallow $(2-3 \mathrm{~m})$ Thalassia testudinum bed $\left(9^{\circ} 18^{\prime} 19.96^{\prime \prime} \mathrm{N}, 82^{\circ} 10^{\prime} 18.48^{\prime \prime} \mathrm{W}\right)$ between Solarte and Bastimentos islands in the Bocas del Toro archipelago of Panama. All individuals were placed into a 201 bucket containing seawater for transit and then transferred to a flowing seawater tank at the Smithsonian Tropical Research Institute Station, where they were allowed to acclimate for $24 \mathrm{~h}$ prior to experiments. After $24 \mathrm{~h}, 5$ individuals were sacrificed for measurements of the natural abundances of $\mathrm{C}$ and $\mathrm{N}$ isotopes $\left(\delta^{13} \mathrm{C}\right.$ and $\left.\delta^{15} \mathrm{~N}\right)$.

While Symbiodinium are found in both the oral arms and bell tissue of Cassiopea spp. hosts, these symbionts are generally in higher abundance in the oral arms compared to the bell $(74.5 \%$ reside in the oral arms and $25.5 \%$ in the bell; Verde \& McCloskey 1998). To investigate $\mathrm{C}$ and $\mathrm{N}$ assimilation in tissues containing both high and low abundances of photosymbionts, we sampled the ends of 4 to 6 oral arms and the center of the bell, respectively. These tissue samples were taken by first carefully severing the manubrium with a razor blade to separate the oral arms from the bell, and then snipping the ends of the oral arms with scissors and removing the center of the bell with a razor blade. Preliminary chlorophyll $a$ (chl a) analyses (as in Freeman et al. 2014) on samples collected as part of this study verified that abundant photosymbiont communities were largely re-

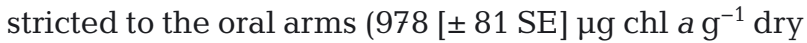
mass in the oral arm vs. 78 [ \pm 16$] \mu g$ chl a g ${ }^{-1}$ dry mass in the bell tissue). 


\section{Experimental setup}

Before the start of the incubation, 11 of filtered (Whatman GF/F) seawater amended with $\mathrm{NaH}^{13} \mathrm{CO}_{3}$ (98 atom percent $[\mathrm{AP}]^{13} \mathrm{C}$ ) and $\mathrm{Na}^{15} \mathrm{NO}_{3}\left(98 \mathrm{AP}^{15} \mathrm{~N}\right)$ (as in Freeman et al. 2013, Baker et al. 2015) was added to each of 18 plastic containers (1.5 l capacity each), and these containers were placed into 2 seawater tanks (acting as constant temperature baths). To assess the role of photosymbionts in $\mathrm{C}$ and $\mathrm{N}$ assimilation within $C$. xamachana, 1 tank was exposed to ambient light ('light treatment'), while the other tank was covered by thick plywood, reducing light to $<1 \%$ of ambient ('dark treatment'), as monitored by HOBO (Onset) data loggers deployed within both tanks over the course of the experiment. To begin the light/dark incubation, a single C. xamachana was added to each of the 9 containers in the dark treatment and 3 C. xamachana were added to each of the 9 containers in the light treatment (see below). After 6 h, a single C. xamachana was removed from each of the 9 containers under both light and dark treatments and processed as above to assess the ${ }^{13} \mathrm{C}$ and ${ }^{15} \mathrm{~N}$ enrichment in each tissue type. After this initial $6 \mathrm{~h}$ incubation, plastic tubing was used to supply a constant flow of seawater to each of the 9 plastic containers (now each holding 2 C. xamachana individuals) within the light treatment, effectively flushing out the enriched incubation water. To follow the fate of the assimilated ${ }^{13} \mathrm{C}$ - and ${ }^{15} \mathrm{~N}$-labeled compounds over time, a single individual was removed from each of these containers after $6 \mathrm{~h}$ and $18 \mathrm{~h}$ and processed as above.

\section{Stable isotope analysis}

Tissue samples were prepared for isotope analyses, and stable isotope compositions were measured at the Stable Isotope Ratio Mass Spectrometry laboratory at the University of Hong Kong, as in Freeman et al. (2014). Natural abundance isotope values in tissues from wild $C$. xamachana and enriched experimental samples are expressed as atom percent $\left(\mathrm{AP}^{13} \mathrm{C}\right.$ and $\left.\mathrm{AP}^{15} \mathrm{~N}\right)$ using equations outlined in Fry (2006) and Freeman et al. (2015). Isotope values are also expressed in delta $(\delta)$ notation in units per mil (\%) to compare isotopic composition between the current study and Freeman et al. (2013) and Baker et al. (2015). Precision of $\delta^{13} \mathrm{C}$ and $\delta^{15} \mathrm{~N}$ was $0.02 \%$ and $0.6 \%$, respectively, as determined by repeated analysis of the internal acetanilide standard ('acet 6'; $70 \% \mathrm{C})$.

\section{Data analysis}

To test for differences in $\mathrm{AP}^{13} \mathrm{C}$ and $\mathrm{AP}^{15} \mathrm{~N}$ values in each tissue type across treatments and between treatment and natural abundance samples, we used a general linear model (GLM). Pairwise comparisons of treatment effects were conducted using the Fisher's least significant difference (LSD) post hoc test. To test for differences in $\mathrm{AP}^{13} \mathrm{C}$ and $\mathrm{AP}^{15} \mathrm{~N}$ values between bell and oral arm tissue of C. xamachana within each treatment, we used paired $t$-tests. Prior to analyses, residuals were tested for normality and homogeneity of variance. All data analyses were carried out using Systat (v.11).

\section{RESULTS}

We found substantial variation in ${ }^{13} \mathrm{C}$ and ${ }^{15} \mathrm{~N}$ enrichment of the bell (general linear model [GLM]: $F=$ 28.8, p $<0.05$ and $F=177.9, \mathrm{p}<0.05$ for ${ }^{13} \mathrm{C}$ and ${ }^{15} \mathrm{~N}$, respectively) and oral arm (GLM: $F=113.0, \mathrm{p}<0.05$ and $F=58.8, \mathrm{p}<0.05$ for ${ }^{13} \mathrm{C}$ and ${ }^{15} \mathrm{~N}$, respectively) tissues across treatments (Fig. 1 and the Appendix).
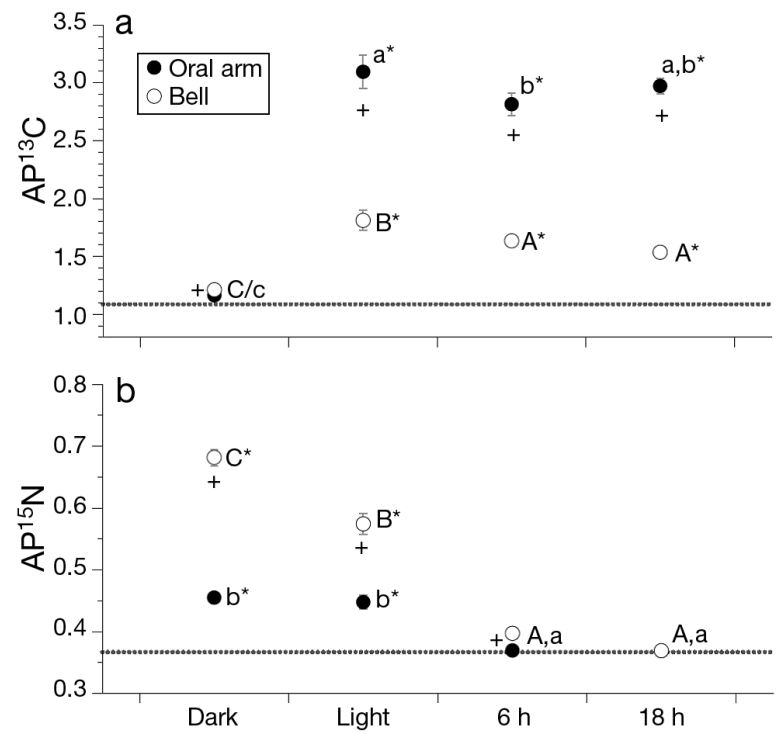

Fig. 1. Mean $( \pm \mathrm{SE})(\mathrm{a})$ atom percent $(\mathrm{AP}){ }^{13} \mathrm{C}$ and $(\mathrm{b}) A \mathrm{P}^{15} \mathrm{~N}$ values in bell (open circles) and oral arm (filled circles) tissue from Cassiopea xamachana individuals incubated for $6 \mathrm{~h}$ under light and dark conditions, and individuals maintained under natural conditions for 6 and $18 \mathrm{~h}$ after exposure to enriched compounds. The dotted line indicates the $\mathrm{AP}^{13} \mathrm{C}$ or $\mathrm{AP}^{15} \mathrm{~N}$ value in natural abundance samples. Letters indicate significant differences across treatments in bell (upper case letters) or oral arm (lower case letters) tissue; ${ }^{*}$ indicates significant enrichment relative to natural abundance tissue samples; + indicates a significant difference between bell and oral arm tissues within a single treatment. $\mathrm{N}=9$ for all experimental samples, and $\mathrm{N}=5$ for natural abundance samples 
Although there was some assimilation of ${ }^{13} \mathrm{C}$ label in the dark (Appendix), $\mathrm{AP}^{13} \mathrm{C}$ values of both tissue types from the dark treatment were similar to natural abundance values (GLM with LSD multiple comparisons test: $p>0.05$; Fig. 1a), and were significantly lower than the $\mathrm{AP}^{13} \mathrm{C}$ values under all 3 light treatments (GLM with LSD multiple comparisons test: $\mathrm{p}<$ 0.05 ; Fig. 1a). $A P^{13} \mathrm{C}$ values were significantly higher in oral arm tissue than bell tissue across all light treatments (paired $t$-test: $\mathrm{p}<0.05$ ), but were higher in the bell under dark conditions (paired $t$-test: $\mathrm{p}<$ 0.05). Although ${ }^{13} \mathrm{C}$ enrichment was generally highest in individuals sampled right after the initial $6 \mathrm{~h}$ exposure, both fractions remained enriched relative to natural abundance samples, even after $18 \mathrm{~h}$ (Fig. 1a).

In contrast, $\mathrm{AP}^{15} \mathrm{~N}$ values of both tissue types from the dark treatment were significantly higher than initial, natural abundance values, and $\mathrm{AP}^{15} \mathrm{~N}$ values of the bell tissue were highest in the dark treatment (GLM with LSD multiple comparisons test: $\mathrm{p}<0.05$; Fig. $1 b) . A P^{15} \mathrm{~N}$ values were elevated in the bell tissue relative to the oral arms in the dark treatment, following the initial $6 \mathrm{~h}$ exposure period, and after $6 \mathrm{~h}$ (paired $t$-test $\mathrm{p}<0.05$ ) in flowing seawater. Unlike $\mathrm{AP}^{13} \mathrm{C}$, the $\mathrm{AP}^{15} \mathrm{~N}$ values from both tissue types were similar to natural abundance values just $6 \mathrm{~h}$ postenrichment (Fig. 1b).

\section{DISCUSSION}

We provide evidence supporting the contention that photosymbionts (i.e. Symbiodinium; LaJeunesse 2002, Coffroth \& Santos 2005, Thornhill et al. 2006) within the oral arms and bell tissue of Cassiopea xamachana are capable of efficient $\mathrm{C}$ fixation. Enrichment of oral arm tissue was striking (mean $\pm \mathrm{SE}$ $\delta^{13} \mathrm{C}$ values of $\sim 1850 \pm 137 \%$; Appendix) and was over $6 \times$ greater than the average photosymbionthosting Caribbean sponge (range of $100-800 \%$; average of $\sim 300 \%$; Freeman et al. 2013) and octocoral (range of $<100-500 \%$, average of $\sim 220 \%$; Baker et al. 2015). Even bell tissue was enriched $\left(\delta^{13} \mathrm{C}\right.$ values of $\sim 650 \pm 82 \%$ ) relative to most members of these other functional groups, suggesting that C. xamachana holobionts from our study are functioning as autotrophs under ambient light conditions and are fixing more $\mathrm{C}$ than is required for respiration alone (Verde \& McCloskey 1998). Indeed, with a daily gross photosynthesis to respiration ratio of 2.04 (Welsh et al. 2009), photosymbiont productivity in Cassiopea is well above the compensation point of
1.0 and higher than that of Caribbean sponges and octocorals (Freeman et al. 2013, Baker et al. 2015).

By hosting symbionts, C. xamachana holobionts are able to assimilate ${ }^{15} \mathrm{NO}_{3}$ (Wilkerson \& Kremer 1992, Pitt et al. 2009, Niggl et al. 2010). In fact, after 6 h, $C$. xamachana were as enriched as, or more enriched than, some photosymbiont-hosting sponge species (C. xamachana $\delta^{15} \mathrm{~N}$ values of $\sim 200-800 \%$ [Appendix] vs. sponge range of $\sim 60-2300 \%$; average of $\sim 600 \%$; Freeman et al. 2013). Interestingly, although the assimilation of $\mathrm{NH}_{4}{ }^{+}$and $\mathrm{NO}_{\mathrm{x}}$ by symbiotic scyphozoans is commonly ascribed to photosymbiont metabolism (Wilkerson \& Kremer 1992, Jantzen et al. 2010, Niggl et al. 2010), light-independent ${ }^{15} \mathrm{~N}$ enrichment in both the bell and oral arm tissue in our study also implicates non-photosynthetic microbial taxa in C. xamachana $\mathrm{N}$ metabolism (Welsh et al. 2009, Jantzen et al. 2010). While dark assimilation by photosymbionts may account for some of this enrichment, efficient dark ${ }^{15} \mathrm{NO}_{3}$ assimilation in the bell tissue, where photosymbiont abundance is lowest (Verde \& McCloskey 1998), further supports the role of non-photosynthetic microbes in C. xamachana $\mathrm{N}$ metabolism.

Our enrichment data suggest a zonation of microbial activity within the C. xamachana holobiont, pairing abundant and productive photosymbiont communities (Verde \& McCloskey 1998, Estes et al. 2003) in the oral arms with microbes capable of efficient $\mathrm{N}$ metabolism in the bell tissue. With photosymbiontderived $\mathrm{C}$ potentially fueling the assimilation of ambient or porewater $\mathrm{N}$ released during Cassiopea pumping activity (Verde \& McCloskey 1998, Welsh et al. 2009, Jantzen et al. 2010), this zonation may optimize nutrient acquisition in oligotrophic waters. Although nitrifying bacteria within Cassiopea have been implicated in the release of $\mathrm{NO}_{\mathrm{x}}$ in the dark (Welsh et al. 2009), investigations into the Cassiopea microbiome and the distribution of microbial groups within and on the surface of a Cassiopea individual are certainly warranted to better elucidate the metabolic pathways available to the host (Pitt et al. 2009) and to better understand the potential coupling between photosymbiont-derived $\mathrm{C}$ and transformations of $\mathrm{N}$ in the bell and animal-sediment interface.

With low levels of ${ }^{15} \mathrm{NO}_{3}$ assimilation relative to ${ }^{13} \mathrm{C}$ fixation in the current study and a low total $\mathrm{N}\left(\mathrm{NH}_{4}{ }^{+}\right.$ and $\mathrm{NO}_{\mathrm{x}}$ ) uptake rate relative to photosynthetic rate (Welsh et al. 2009), Cassiopea might rely on exogenous sources of $\mathrm{N}$ such as zooplankton or dissolved organic $\mathrm{N}$ via predation for growth (Wilkerson \& Kremer 1992, Pitt et al. 2009, Welsh et al. 2009). In addition, the loss of ${ }^{15} \mathrm{~N}$ signal only $6 \mathrm{~h}$ after the initial in- 
cubation implies that microbially derived ${ }^{15} \mathrm{~N}$ atoms are rapidly processed within the C. xamachana holobiont. Although the loss of DIN from Cassiopea is negligible (Pitt et al. 2009, E. Stoner unpubl. data), the ${ }^{15} \mathrm{~N}$ signal may have been diluted by heterotrophic feeding on natural sources of $\mathrm{N}$ in the incubation containers once flowing seawater was added, the recycling of host-derived N in the Cassiopea-Symbiodinium symbiosis (Pitt et al. 2009), or the loss of ${ }^{15} \mathrm{~N}$-labeled organic matter in mucus (Niggl et al. 2010). In contrast, the strong ${ }^{13} \mathrm{C}$ signal in both bell and oral arm tissue remained or was only slightly diminished, even after $18 \mathrm{~h}$ in flowing seawater. While this certainly supports the contention that photosymbiont-derived $\mathrm{C}$ is integrated into C. xamachana holobiont biomass and is a dominant source of $\mathrm{C}$ to these jellyfish, additional research is needed that follows the integration and loss of ${ }^{13} \mathrm{C}$ and ${ }^{15} \mathrm{~N}$ over shorter (1-5 h) and longer (days) time periods to better understand $\mathrm{C}$ and $\mathrm{N}$ processing within C. xamachana.

Trends in ${ }^{13} \mathrm{C}$ and ${ }^{15} \mathrm{~N}$ enrichment between the bell and oral arm tissue may reflect the rapid translocation of biomolecules from symbionts concentrated in the oral arms to host cells in the bell tissue (Verde \& McCloskey 1998). However, because this translocation would also be reflected in the continued transfer of ${ }^{13} \mathrm{C}$ - and ${ }^{15} \mathrm{~N}$-labeled compounds after the initial incubation, leading to diminished enrichment in the oral arm tissue and higher enrichment in the bell tissue, we suggest that this is unlikely. Additional studies investigating the transfer of ${ }^{13} \mathrm{C}$ - and/or ${ }^{15} \mathrm{~N}$ labeled compounds from symbiont to host are certainly warranted. Unfortunately, although previous studies have successfully isolated Symbiodinium (Verde \& McCloskey 1998, Stat et al. 2008) or Symbiodinium and animal cells (Wilkerson \& Kremer 1992) from symbiotic scyphozoans via homogenization followed by centrifugation, the organic matter content of these organisms is low $(<\sim 3 \%$; Pitt et al. 2009), and previous research using these methods found no indication of the translocation of ${ }^{15} \mathrm{~N}$ labeled compounds, even after $33 \mathrm{~h}$ (Wilkerson \& Kremer 1992). Future studies coupling ${ }^{13} \mathrm{C}$ - and ${ }^{15} \mathrm{~N}$ enriched compounds with higher-resolution technology like NanoSIMS may better elucidate this transfer (Kopp et al. 2013).

This study provides initial evidence that symbiont metabolism within C. xamachana is comparable to other common benthic marine invertebrates, supporting the contention that Cassiopea holobionts have an important role in the productivity and nutrient dynamics of their local environment. As a common member of shallow, benthic communities in tropical and subtropical areas worldwide, with locally high densities in some areas (Jantzen et al. 2010, Niggl et al. 2010, Stoner et al. 2011), Cassiopea may drive benthic photosynthetic oxygen production and act as a sink for local inorganic nutrients (Welsh et al. 2009). While Cassiopea consume organic sources of $\mathrm{N}$, members of their symbiont community also allow for DIN assimilation, potentially contributing to higher growth rates in response to elevated nutrients (E. Stoner unpubl. data) and their proliferation and larger size in areas in close proximity to human populations and anthropogenic inputs (Stoner et al. 2011). Finally, through the release of copious amounts of mucus, symbiont-derived nutrients may ultimately act as a trophic link between benthic and pelagic food webs in these systems (Verde \& McCloskey 1998, Niggl et al. 2010).

Acknowledgements. We thank R. Collin, G. Jacome, and P. Gondola at the Smithsonian Tropical Research Institute in Bocas del Toro, Panama, for logistical support. Financial support for this project came from a postdoctoral fellowship awarded to C.J.F. from the Smithsonian Institution's Marine Global Earth Observatory (MarineGEO) and Tennenbaum Marine Observatories Network (TMON) initiatives. This is contribution number 1023 from the Smithsonian Marine Station at Fort Pierce, Florida.

\section{LITERATURE CITED}

Baker AC (2003) Flexibility and specificity in coral-algal symbiosis: diversity, ecology, and biogeography of Symbiodinium. Annu Rev Ecol Evol Syst 34:661-689

Baker DM, Andras JP, Jordán-Garza A, Fogel ML (2013) Nitrate competition in a coral symbiosis varies with temperature among Symbiodinium clades. ISME J 7 : 1248-1251

Baker DM, Freeman CJ, Knowlton N, Thacker RW, Kim K, Fogel ML (2015) Productivity links morphology, symbiont specificity and bleaching in the evolution of Caribbean octocoral symbioses. ISME J 9:2620-2629

> Coffroth MA, Santos SR (2005) Genetic diversity of symbiotic dinoflagellates in the genus Symbiodinium. Protist 156:19-34

- Estes AM, Kempf SC, Henry RP (2003) Localization and quantification of carbonic anhydrase activity in the symbiotic scyphozoan Cassiopea xamachana. Biol Bull (Woods Hole) 204:278-289

> Freeman CJ, Thacker RW, Baker DM, Fogel M (2013) Quality or quantity: Is nutrient transfer driven more by symbiont identity and productivity than by symbiont abundance? ISME J 7:1116-1125

Freeman CJ, Easson CG, Baker DM (2014) Metabolic diversity and niche structure in sponges from the Miskito Cays, Honduras. Peer J 2:e695

Freeman CJ, Baker DM, Easson CG, Thacker RW (2015) Shifts in sponge-microbe mutualisms across an experimental irradiance gradient. Mar Ecol Prog Ser 526:41-53

Fry B (2006) Stable isotope ecology. Springer, New York, NY 
Grover R, Maguer J, Reynaud-Vaganay S, Ferrier-Pagès C (2002) Uptake of ammonium by the scleractinian coral Stylophora pistillata: effect of feeding, light, and ammonium concentrations. Limnol Oceanogr 47:782-790

Jantzen C, Wild C, Rasheed M, El-Zibdah M, Richter C (2010) Enhanced pore-water nutrient fluxes by the upside-down jellyfish Cassiopea sp. in a Red Sea coral reef. Mar Ecol Prog Ser 411:117-125

Kopp C, Pernice M, Domart-Coulon I, Djediat C and others (2013) Highly dynamic cellular-level response of symbiotic coral to a sudden increase in environmental nitrogen. MBio 4:e00052-13

LaJeunesse T (2002) Diversity and community structure of symbiotic dinoflagellates from Caribbean coral reefs. Mar Biol 141:387-400

Moran NA (2007) Symbiosis as an adaptive process and source of phenotypic complexity. Proc Natl Acad Sci USA 104:8627-8633

Muscatine L, Porter JW (1977) Reef corals: mutualistic symbioses adapted to nutrient-poor environments. BioScience 27:454-460

Niggl W, Naumann MS, Struck U, Manasrah R, Wild C (2010) Organic matter release by the upside-down jellyfish Cassiopea sp. fuels pelagic food webs in coral reefs. J Exp Mar Biol Ecol 384:99-106

Pitt KA, Welsh DT, Condon RH (2009) Influence of jellyfish blooms on carbon, nitrogen, and phosphorus cycling and plankton production. Hydrobiologia 616:133-149

Stat M, Morris E, Gates RD (2008) Functional diversity in coral-dinoflagellate symbiosis. Proc Natl Acad Sci USA 105:9256-9261

Stoner EW, Layman CA, Yeager LA, Hassett HM (2011) Effects of anthropogenic disturbance on the abundance and size of epibenthic jellyfish Cassiopea spp. Mar Pollut Bull 62:1109-1114

Thornhill DJ, Daniel MW, LaJeunesse TC, Schmidt GW, Fitt WK (2006) Natural infections of aposymbiotic Cassiopea xamachana scyphistomae from environmental pools of Symbiodinium. J Exp Mar Biol Ecol 338:50-56

Verde EA, McCloskey LR (1998) Production, respiration, and photophysiology of the mangrove jellyfish Cassiopea xamachana symbiotic with zooxanthellae: effect of jellyfish size and season. Mar Ecol Prog Ser 168:147-162

> Weisz JB, Massaro AJ, Ramsby BD, Hill MS (2010) Zooxanthellar symbionts shape host sponge trophic status through translocation of carbon. Biol Bull (Woods Hole) 219:189-197

Welsh DT, Dunn RJK, Meziane T (2009) Oxygen and nutrient dynamics of the upside down jellyfish (Cassiopea sp.) and its influence on benthic nutrient exchanges and primary production. Hydrobiologia 635:351-362

Wilkerson FP, Kremer P (1992) DIN, DON and $\mathrm{PO}_{4}$ flux by a medusa with algal symbionts. Mar Ecol Prog Ser 90: $237-250$

Zilber-Rosenberg I, Rosenberg E (2008) Role of microorganisms in the evolution of animals and plants: the hologenome theory of evolution. FEMS Microbiol Rev 32:723-735

\section{Appendix}

Mean $( \pm \mathrm{SE})$ isotope values in delta notation $\left(\delta^{13} \mathrm{C}\right.$ and $\left.\delta^{15} \mathrm{~N}\right)$ and atom percent $\left(\mathrm{AP}^{13} \mathrm{C}\right.$ and $\left.\mathrm{AP}{ }^{15} \mathrm{~N}\right)$ from Cassiopea xamachana oral arm and bell tissue from initial (natural abundance) and experimental conditions (individuals incubated for $6 \mathrm{~h}$ under light or dark conditions and individuals maintained under natural conditions for 6 and $18 \mathrm{~h}$ after exposure to enriched tracers)

\begin{tabular}{|c|c|c|c|c|c|c|c|c|}
\hline & \multicolumn{2}{|c|}{$\longrightarrow \delta^{13} \mathrm{C}$} & \multicolumn{2}{|c|}{$-\delta^{15} \mathrm{~N}-$} & \multicolumn{2}{|l|}{$-\mathrm{AP}^{13} \mathrm{C}$} & \multicolumn{2}{|c|}{$-\mathrm{AP}^{15} \mathrm{~N}$} \\
\hline & Oral arm & Bell & Oral arm & Bell & Oral arm & Bell & Oral arm & Bell \\
\hline Initial & $-18.2(0.37)$ & $-16.8(0.39)$ & $0.14(0.22)$ & $2.48(0.18)$ & $1.09(<0.01)$ & $1.09(<0.01)$ & $0.37(<0.01)$ & $0.37(<0.01)$ \\
\hline Dark & $53.1(3.27)$ & $96.9(11.9)$ & $243.8(13.5)$ & $867.9(36.5)$ & $1.16(<0.01)$ & $1.21(0.01)$ & $0.46(<0.01)$ & $0.68(0.01)$ \\
\hline Light & $1859.7(136.8)$ & $650.0(81.9)$ & $223.6(30.5)$ & $571.9(45.6)$ & $3.1(0.14)$ & $1.81(0.09)$ & $0.45(0.01)$ & $0.57(0.02)$ \\
\hline $6 \mathrm{~h}$ & $1593.0(90.4)$ & $486.0(33.6)$ & $9.3(0.43)$ & $84.8(14.7)$ & $2.82(0.10)$ & $1.63(0.04)$ & $0.37(<0.01)$ & $0.40(<0.01)$ \\
\hline $18 \mathrm{~h}$ & $1742.0(63.9)$ & $394.9(43.6)$ & $7.28(0.39)$ & $8.37(0.87)$ & $2.97(0.07)$ & $1.54(0.05)$ & $0.37(<0.01)$ & $0.37(<0.01)$ \\
\hline
\end{tabular}

Editorial responsibility: Robert Condon, Wilmington, North Carolina, USA
Submitted: August 13, 2015; Accepted: January 8, 2016 Proofs received from author(s): February 5, 2016 